Revista Brasil. Bot., V.25, n.3, p.259-267, set. 2002

\title{
Florística e estrutura do componente epifítico vascular em floresta ombrófila mista aluvial do rio Barigüi, Paraná, Brasil
}

\author{
RODRIGO A. KERSTEN ${ }^{1,3}$ e SANDRO M. SILVA ${ }^{2}$
}

(recebido: 11 de outubro de 2001; aceito: 10 de abril de 2002)

\begin{abstract}
Floristic composition and structure of the vascular epiphyte component of a subtropical ombrophilous alluvial forest of Barigüi river, Paraná, Brazil). Structure and floristic composition of the vascular epiphyte component of a subtropical ombrophilous alluvial forest located along the Barigüi river, Southern Brazil (25 $34^{\prime}$ S and $49^{\circ} 20^{\prime} \mathrm{W}$ ) is described. The qualitative survey was carried out in an 8.6 ha area while the quantitative survey was done on 110 assorted trees. The surveyed trees were divided into tree strata (low trunk, high trunk and canopy). In each stratum, scores were given (one to three) for all of the occurring epiphytic species according to its abundance. We listed 49 vascular epiphytic species (16 Pteridophyta, 23 Liliopsida and 10 Magnoliopsida) from 28 genera spread into 12 families, however only 34 species were found for the quantitative survey. The richest families were Orchidaceae, Polypodiaceae and Bromeliaceae, while Pleurothallis, Tillandsia and Oncidium made up the richest genera. Areas presenting the closest floristic similarity with this survey are located in the Curitiba County, state of Paraná, Brasil. For the quantitative survey, Microgramma squamulosa (Kaulf.) de la Sota, Pleopeltis angusta Humb. \& Bonpl. ex Kunth, Peperomia catharinae Miq. and Polypodium hirsutissimum Raddi were the most important species. The number of species found for single host-trees ranged from zero to 13 while scores for abundance (VA) ranged from zero to 24 . The canopy presented the highest abundance with a VA equal to 622 (high trunk $=308$ and low trunk $=110$ ).

RESUMO - (Composição florística e estrutura do componente epifítico vascular em floresta ombrófila mista aluvial do Rio Barigüi, Paraná, Brasil). O estudo das epífitas vasculares foi realizado em floresta ombrófila mista aluvial do rio Barigüi, município de Araucária (2534' S e 49²0' W); o levantamento qualitativo foi realizado em uma área aproximada de 8,6 ha. Para o estudo quantitativo foram sorteados 110 forófitos, divididos em três estratos (fuste baixo, fuste alto e copa). Em cada estrato foram atribuídas notas de abundância para as espécies epifíticas ocorrentes. No levantamento florístico foram encontradas 49 espécies (16 de Pteridophyta, 23 de Liliopsida e 10 de Magnoliopsida), das quais 34 foram observadas na amostragem quantitativa. As famílias e gêneros mais ricos foram: Orchidaceae, Polypodiaceae e Bromeliaceae, e Pleurothallis, Tillandsia e Oncidium. As áreas de maior similaridade florística com este estudo localizam-se no município de Curitiba (PR). As espécies mais importantes quantitativamente foram Microgramma squamulosa (Kaulf.) de la Sota, Pleopeltis angusta Humb. \& Bonpl. ex Kunth, Peperomia catharinae Miq. e Polypodium hirsutissimum Raddi. Em um mesmo forófito, o número de espécies ocorrentes variou de zero a 13, enquanto a soma das notas de abundância para as epífitas variou de zero a 24 . A copa apresentou a maior abundância de epífitos, seguido do fuste alto e do fuste baixo.
\end{abstract}

Key words - Vascular epiphytes, floristic composition, vertical distribution, Araucaria forest

\section{Introdução}

Epífitas, conforme definidas por Madison (1977), são plantas que em algum estádio de sua vida utilizamse de suporte, mas não diretamente de nutrientes, das plantas em que se apóiam (forófitos), sem estarem conectadas ao solo. Apesar de serem responsáveis por parte significativa da diversidade das florestas tropicais, são ainda pouco estudadas quando comparadas a outros componentes destas florestas.

Dentre os estudos realizados sobre a composição florística da comunidade epifítica vascular no Brasil

\footnotetext{
1. Universidade Estadual de Londrina, Departamento de Biologia Animal e Vegetal, Caixa Postal 6001, 86051-990 Londrina, PR, Brasil.

2. Fundação O Boticário de Proteção à Natureza.

4._Autor para correspondência: kersten@bol.com.br
}

destacam-se os trabalhos de Pinto et al. (1995) em um fragmento de floresta no Estado de São Paulo, de Aguiar et al. (1981) no Rio Grande do Sul e de Dislich \& Mantovani (1998) na cidade de São Paulo, todos realizados em área de ocorrência da floresta estacional semidecidual.

Na região de ocorrência da floresta ombrófila densa pode-se citar o estudo qualitativo feito por Fontoura et al. (1997) na Reserva de Macaé de Cima, Rio de Janeiro, enquanto em áreas de planície costeira podem ser ressaltados os estudos realizados por Waechter (1986, 1992, 1998) no Rio Grande do Sul, por Labiak \& Prado (1998), no norte de Santa Catarina, por Piliackas et al. (2000) em um manguezal de Ubatuba, São Paulo e por Kersten \& Silva (2001) no Estado do Paraná.

Na região de ocorrência da floresta ombrófila mista (floresta com Araucaria) são observados os 
levantamentos qualitativos executados por Cervi \& Dombrowski (1985), Cervi et al. (1988) e Dittrich et al. (1999), todos na região de Curitiba, PR.

Este trabalho teve como objetivos levantar as espécies epifíticas ocorrentes em uma área de floresta aluvial na região de ocorrência da floresta com Araucaria, suas respectivas abundâncias e padrões de distribuição vertical na comunidade.

\section{Material e métodos}

O levantamento das epífitas vasculares foi realizado em uma área de aproximadamente 8,6 ha da Refinaria Presidente Getúlio Vargas (Repar/Petrobras), no município de Araucária, PR (2534' S e 49²0' W), em altitude média de 900 m s.n.m, a cerca de $20 \mathrm{~km}$ ao sul da capital do Estado do Paraná. O clima é do tipo $\mathrm{Cfb}$ (subtropical úmido, mesotérmico, com verões frescos e geadas freqüentes, sem estação seca definida), com temperaturas média anuais de $16,5^{\circ} \mathrm{C}$, sendo $12,7^{\circ} \mathrm{C}$ a temperatura média do mês mais frio (julho) e 20,3 ${ }^{\circ} \mathrm{C}$ a do mês mais quente (fevereiro). A precipitação média anual é de $1.400 \mathrm{~mm}$, sendo os meses do verão (janeiro a março) os mais chuvosos (Siqueira et al. 2001).

A área está incluída em região com predomínio de migmatitos pertencentes ao Complexo Cristalino, de idade pré-cambriana, além de áreas constituídas por sedimentos da formação Guabirotuba. O solo da área é formado por associações entre gleissolos e cambissolos, na sua maioria com textura argilosa e relevo plano, com diversas carcaterísticas relacionadas ao hidromorfismo (Siqueira et al. 2001).

A vegetação natural da área de estudo é constituida por extensas áreas campestres interrompidas por inclusões de floresta ombrófila mista, destacadamente em locais mais úmidos, como entorno de nascentes e ao longo dos rios e córregos, conhecidas como "capões" e/ou "matas ciliares" (Maack 1981). Conforme o sistema de classificação da vegetação brasileira de Veloso et al. (1991), a área está incluída na região da floresta ombrófila mista, representada pela subformação aluvial, característica por ocorrer em locais diretamente influenciados pelo regime fluvial de rios de menor ou maior extensão. O estrato arbóreo dessa floresta tem densidade aproximada de 3.491 ind.ha $^{-1}$ e altura média de 11,3 m (Siqueira et al. 2001). Neste estudo foram amostradas 27 espécies, sendo Sebastiania commersoniana (Euphorbiaceae) a espécie dominante, com cerca de $68 \%$ dos indivíduos amostrados. Outras espécies importantes foram Allophylus edulis (Sapindaceae), Schinus terebinthifolius (Anacardiaceae), Blepharocalyx salicifolius (Myrtaceae) e Vitex montevidensis (Verbenaceae).

Para o estudo qualitativo, foram realizadas excursões semanais durante aproximadamente um ano, sendo coletadas e herborizadas todas as espécies encontradas férteis, indivíduos estéreis foram marcados para posterior coleta ou levados para cultivo até a floração para então serem registrados como exemplares de referência. Todo o material coletado foi herborizado conforme os procedimentos usuais em levantamentos florísticos e incorporado aos Herbários do Departamento de Botânica da Universidade Federal do Paraná (UPCB) e Escola de Floresta do Paraná (EFP). Os nomes das espécies foram verificados no Index Kewensis (1993), sendo utilizadas as abreviaturas dos autores sugeridas por Brummitt \& Powell (1992). As espécies levantadas foram classificadas em categorias ecológicas, de acordo com sua relação com o forófito (Kersten \& Silva 2001).

Para o estudo quantitativo foram escolhidas aleatoriamente, em campo, 110 árvores com no mínimo $30 \mathrm{~cm}$ de perímetro a 1,3 m de altura do solo (PAP), totalizando 13 espécies. Os forófitos foram divididos em três estratos para efeito da análise de distribuição vertical das epífitas: fuste baixo (até 1,5 $\mathrm{m}$ do solo), fuste alto (de 1,5 $\mathrm{m}$ do solo até a base da copa) e copa, nas quais foram registradas todas as espécies epifíticas ocorrentes. Para cada espécie foi atribuída uma nota referente à sua respectiva abundância, a saber: 1 um ou poucos indivíduos isolados; 2 - agrupamentos mais extensos ou diversos indivíduos isolados; 3 - abundante, formando em muitos casos uma cobertura quase contínua no forófito.

Foram calculadas as freqüências absolutas de ocorrência nos estratos (FAr) e nos indivíduos forofíticos (FAi). O valor de importância epifítico (VIE) foi calculado com base nas notas atribuídas às epífitas. As fórmulas empregadas para estas análises (modificadas de Waechter 1998) foram as seguintes: $\mathrm{FAr}=\left(\mathrm{nr}^{-n a^{-1}}\right) \cdot 100 ; \mathrm{FAi}=$ $\left(\right.$ ni.nt $\left.{ }^{-1}\right) \cdot 100 ; \mathrm{VIE}=\left[\mathrm{vt} \cdot(\Sigma \mathrm{vt})^{-1}\right] \cdot 100$, onde $\mathrm{nr}=$ número de regiões com ocorrência da espécie epifítica; na $=$ número total de regiões amostradas; ni = número de indivíduos com ocorrência da espécie; $\mathrm{nt}=$ número total de indivíduos; $v t=$ somatória das notas obtidas pela espécie. Foi também calculada a nota média dada às espécies nos intervalos, na tentativa de exprimir sua abundância média sobre os forófitos; desta forma, uma espécie que tenha obtido média superior a 2 ocupa sempre grandes áreas do forófito, outra com média proxima ou igual a 1 apresenta-se, geralmente, pouco expressiva sobre os indivíduos arbóreos. Outro parâmetro utilizado foi a somatória das notas das espécies epifíticas, denominada valor absoluto (VA - estimativa da abundância e da riqueza) nos intervalos ou árvores considerados. A partir dos dados de ocorrência das espécies sobre os indivíduos forofíticos, foi calculado o índice de diversidade de Shannon (H'). Visando o estabelecimento de relações entre riqueza e abundância das epífitas com os forófitos, estes foram tratados em classes de diâmetro de $5 \mathrm{~cm}$ e em classes de altura de $1 \mathrm{~m}$, sendo empregados testes de correlação de Spearman ( $\mathrm{p}$ 0,05) para tal finalidade (Krebs 1998). 


\section{Resultados}

No levantamento florístico foram registradas 51 espécies de epífitas vasculares, distribuídas em 28 gêneros e 12 famílias; as pteridófitas contribuíram com seis famílias, 11 gêneros e 16 espécies, e as magnoliófitas, com 17 gêneros e 35 espécies, sendo representadas por seis famílias, duas de Liliopsida (11 gêneros e 25 espécies) e quatro de Magnoliopsida (seis gêneros e 11 espécies). Em riqueza florística destacaram-se Orchidaceae (16 espécies - 33\%), Polypodiaceae e Bromeliaceae (ambas com nove espécies - 18\%); cinco famílias foram representadas por apenas uma espécie. Pleurothallis (Orchidaceae) foi o gênero mais rico, com seis espécies (13\%), seguido por Tillandsia (Bromeliaceae) com seis espécies (12\%) e Oncidium (Orchidaceae), com quatro espécies (8\%) e Lepismium (Cactaceae), Peperomia (Piperaceae) e Polypodium (Polypodiaceae) com três espécies cada; 16 gêneros apresentaram apenas uma espécie (tabela 1).

A distribuição das espécies epifíticas registradas na área conforme as categorias ecológicas de relação com o forófito (tabela 1) evidenciou o predomínio de holoepífitas características (43 espécies - 84\%), dentre as quais destacou-se Orchidaceae, em que todas as espécies foram enquadradas em tal categoria. As holoepífitas acidentais foram representadas por quatro espécies (8\%) e as facultativas por somente 3 espécies $(6 \%)$.

Tabela 1. Lista das espécies e morfoespécies observadas na área de floresta aluvial do rio Barigüi na Repar/Petrobras, município de Araucária, Paraná, e suas categorias ecológicas $(\mathrm{HLC}=$ holoepífito característico, HLF = holoepífito facultativo, HLA = holoepífito acidental) e número de registro da exsicata no Herbário UPCB.

\begin{tabular}{|c|c|c|}
\hline FAMÍLIA/ESPÉCIE & Cat. & UPCB \\
\hline \multicolumn{3}{|l|}{ ASPLENIACEAE } \\
\hline Asplenium clausenii Hier. & HLF & 44192 \\
\hline Asplenium gastonis Fée & HLF & 44203 \\
\hline \multicolumn{3}{|l|}{ BROMELIACEAE } \\
\hline Aechmea distichantha Lem. & HLF & 44193 \\
\hline Aechmea recurvata (Klotzsch) L.B. Sm. & HLC & 25990 \\
\hline Tillandsia crocata (E. Morren) Baker & HLC & 32438 \\
\hline Tillandsia mallemontii Glaziou ex Mez & HLC & 44249 \\
\hline Tillandsia recurvata $(\mathrm{L}.) \mathrm{L}$. & HLC & 44296 \\
\hline Tillandsia stricta Sol. & HLC & 44228 \\
\hline Tillandsia tenuifolia $\mathrm{L}$. & HLC & 43995 \\
\hline Tillandsia usneoides L. & HLC & 44176 \\
\hline Vriesea reitzii Leme \& Costa, Andrea & HLC & 43964 \\
\hline \multicolumn{3}{|l|}{ CACTACEAE } \\
\hline Hatiora salicornioides Britton \& Rose & HLC & 44188 \\
\hline Lepismium cruciforme (Vell.) Miq. & HLC & 44180 \\
\hline Lepismium houlletianum (Lem.) Barthlott & HLC & 25995 \\
\hline Lepismium lumbricoides (Lem.) Barthlott & HLC & 43957 \\
\hline Rhipsalis teres Steud. & HLC & 40823 \\
\hline \multicolumn{3}{|l|}{ COMMELINACEAE } \\
\hline Tradescantia fluminensis Vell. & HLA & 42199 \\
\hline \multicolumn{3}{|l|}{ DRYOPTERIDACEAE } \\
\hline Diplazium petersenii (Kuntze) Christ & HLA & 43470 \\
\hline Rumohra adiantiformis (G. Forst) Ching & HLA & 44715 \\
\hline \multicolumn{3}{|l|}{ GESNERIACEAE } \\
\hline Sinningia douglasii (Lindl.) Chautems & HLC & 44714 \\
\hline \multicolumn{3}{|l|}{ HYMENOPHYLLACEAE } \\
\hline Trichomanes pyxidiferum $\mathrm{L}$. & HLC & 27856 \\
\hline \multicolumn{3}{|l|}{ ORCHIDACEAE } \\
\hline Campylocentrum aromaticum Barb. Rodr. & HLC & 44203 \\
\hline Campylocentrum burchelli Cogn. & HLC & 44244 \\
\hline
\end{tabular}


(cont.)

\begin{tabular}{|c|c|c|}
\hline FAMÍLIA/ESPÉCIE & Cat. & UPCB \\
\hline \multicolumn{3}{|l|}{ ORCHIDACEAE } \\
\hline Capanemia australis Barb. Rodr. & HLC & 43948 \\
\hline Cryptophoranthus juergensii Schltr. & HLC & \\
\hline Leptotes unicolor Barb. Rodr. & HLC & 43982 \\
\hline Maxillaria acicularis Lindl. & HLC & 36146 \\
\hline Oncidium loefgrenii Cogn. & HLC & 27116 \\
\hline Oncidium longicornu Mutel & HLC & 44699 \\
\hline Oncidium sp. & HLC & - \\
\hline Pleurothallis adiri Brade & HLC & 43469 \\
\hline Pleurothallis aveniformis Hoehne & HLC & 44567 \\
\hline Pleurothallis grobyi Lindl. & HLC & 44291 \\
\hline Pleurothallis hatschbachii Schltr. & HLC & 44717 \\
\hline Pleurothallis hygrophila Barb. Rodr. & HLC & 44253 \\
\hline Pleurothallis sonderana $\mathrm{Rchb}$. f. & HLC & 44657 \\
\hline Psygmorchis pusilla (L.) Dodson \& Dressler & HLC & 44693 \\
\hline \multicolumn{3}{|l|}{ PIPERACEAE } \\
\hline Peperomia catharinae Miq. & HLC & 44194 \\
\hline Peperomia tetraphylla (G. Forst) Hook. \& Arn. & HLC & 44207 \\
\hline Peperomia trineura Miq. & HLC & 44206 \\
\hline \multicolumn{3}{|l|}{ POLYPODIACEAE } \\
\hline Campyloneurum austrobrasilianum (Alston) de la Sota & HLC & 27858 \\
\hline Campyloneurum nitidum (Kaulf.) C. Presl. & HLC & 44256 \\
\hline Microgramma squamulosa (Kaulf.) de la Sota & HLC & 44217 \\
\hline Pecluma sicca (Lindm.) M.G. Price & HLC & 44237 \\
\hline Pleopeltis angusta Humb. \& Bonpl. ex Kunth & HLC & 43965 \\
\hline Pleopeltis macrocarpa (Willd.) Kaulf. & HLC & 43981 \\
\hline Polypodium catharinae Langsd. \& Fisch. & HLC & 43952 \\
\hline Polypodium hirsutissimum Raddi & HLC & 43971 \\
\hline Polypodium pleopeltides Fée & HLC & 43951 \\
\hline \multicolumn{3}{|l|}{ PTERIDACEAE } \\
\hline Doryopteris nobilis (Moore) C. Chr. & HLA & 42251 \\
\hline \multicolumn{3}{|l|}{ VITTARIACEAE } \\
\hline Vittaria lineata (L.) Sm. & HLC & 43154 \\
\hline
\end{tabular}

No estudo quantitativo foram registradas 787 ocorrências de epífitos vasculares, representados por 34 espécies, 21 gêneros e 10 famílias. O índice de diversidade de Shannon estimado para a amostra foi de $\mathrm{H}^{\prime}=2,706$ e a equidade $\mathrm{J}=0,767$.

Microgramma squamulosa (Polypodiaceae) destacou-se como a espécie mais importante, com valor de importância epifítica (VIE) equivalente a 27,3 e nota média igual a 1,7 (tabela 2); esta espécie ocorreu em $82 \%$ dos forófitos e $50 \%$ dos estratos amostrados. A segunda espécie em importância, Pleopeltis angusta (Polypodiaceae), foi amostrada em 95\% dos forófitos e $55 \%$ dos estratos (VIE $=26,0$ ) e teve como nota média 1,5. Capanemia australis (Orchidaceae) e Polypodium hirsutissimum (Polypodiaceae) obtiveram o mesmo VIE
$(7,9)$, a primeira ocorrendo em $24 \%$ dos intervalos e $55 \%$ dos forófitos e a segunda em $22 \%$ dos intervalos e $54 \%$ dos forófitos. Peperomia catharinae (Piperaceae), quinta espécie em importância (VIE $=7,1$ ), ocorreu em $32 \%$ dos forófitos e $21 \%$ dos estratos amostrados, obtendo nota média igual a 1 . Estas cinco espécies, juntas, totalizam $76,3 \%$ do VIE total obtido na amostra (tabela 2), podendo ser consideradas como dominantes no ambiente epifítico da floresta analisada. Seis espécies (12\%) foram observadas apenas uma vez sendo consideradas, juntamente com as observadas apenas na florística (16 espécies), raras.

Aechmea distichantha (Bromeliaceae) obteve a maior nota média (2,2), seguida por Microgramma squamulosa $(1,7)$, Pleopeltis angusta $(1,5)$ e por duas 
Tabela 2. Espécies encontradas no levantamento quantitativo da floresta ombrófila mista aluvial do rio Barigüi, classificadas segundo o valor de importância epifítica $(n e=$ número absoluto de ocorrências nos estratos, FAe = freqüência absoluta nos estratos, ni = número absoluto de ocorrências nos indivíduos forofíticos, FAi = Freqüência absoluta nos indivíduos forofíticos, valor total = soma das estimativas de abundância, VIE = valor de importância epifítico e nota = nota média obtida).

\begin{tabular}{|c|c|c|c|c|c|c|c|}
\hline Espécie & ne & FAe $(\%)$ & $\mathrm{ni}$ & FAi $(\%)$ & Valor total & VIE & $\overline{\text { nota }}$ \\
\hline Microgramma squamulosa & 165 & 50,0 & 90 & 81,8 & 284 & 27,3 & 1,7 \\
\hline Pleopeltis angusta & 181 & 54,8 & 104 & 94,5 & 270 & 26,0 & 1,5 \\
\hline Capanemia australis & 79 & 23,9 & 60 & 54,5 & 82 & 7,9 & 1,0 \\
\hline Polypodium hirsutissimum & 73 & 22,1 & 59 & 53,6 & 82 & 7,9 & 1,1 \\
\hline Peperomia catharinae & 69 & 20,9 & 35 & 31,8 & 74 & 7,1 & 1,1 \\
\hline Campylocentrum burchelii & 36 & 10,9 & 33 & 30,0 & 37 & 3,6 & 1,0 \\
\hline Pleurothallis aveniformis & 25 & 7,6 & 23 & 20,9 & 28 & 2,7 & 1,1 \\
\hline Lepismium lumbricoides & 18 & 5,5 & 15 & 13,6 & 25 & 2,4 & 1,4 \\
\hline Lepismium houlletianum & 16 & 4,8 & 14 & 12,7 & 22 & 2,1 & 1,4 \\
\hline Campyloneurum austrobrasilianum & 13 & 3,9 & 12 & 10,9 & 16 & 1,5 & 1,2 \\
\hline Aechmea distichantha & 5 & 1,5 & 5 & 4,5 & 11 & 1,1 & 2,2 \\
\hline Polypodium pleopeltides & 10 & 3,0 & 10 & 9,1 & 11 & 1,1 & 1,1 \\
\hline Campyloneurum nitidum & 10 & 3,0 & 7 & 6,4 & 10 & 1,0 & 1,0 \\
\hline Leptotes unicolor & 10 & 3,0 & 7 & 6,4 & 10 & 1,0 & 1,0 \\
\hline Pleurothallis hygrophila & 10 & 3,0 & 8 & 7,3 & 10 & 1,0 & 1,0 \\
\hline Tillandsia stricta & 8 & 2,4 & 7 & 6,4 & 8 & 0,8 & 1,0 \\
\hline Tillandsia tenuifolia & 7 & 2,1 & 5 & 4,5 & 7 & 0,7 & 1,0 \\
\hline Asplenium clausenii & 6 & 1,8 & 6 & 5,5 & 6 & 0,6 & 1,0 \\
\hline Oncidium loefgrenii & 5 & 1,5 & 4 & 3,6 & 6 & 0,6 & 1,2 \\
\hline Pecluma sicca & 6 & 1,8 & 5 & 4,5 & 6 & 0,6 & 1,0 \\
\hline Pleurothallis sonderana & 5 & 1,5 & 4 & 3,6 & 5 & 0,5 & 1,0 \\
\hline Campylocentrum aromaticum & 4 & 1,2 & 4 & 3,6 & 4 & 0,4 & 1,0 \\
\hline Oncidium longicornu & 4 & 1,2 & 4 & 3,6 & 4 & 0,4 & 1,0 \\
\hline Pleopeltis macrocarpa & 4 & 1,2 & 4 & 3,6 & 4 & 0,4 & 1,0 \\
\hline Trichomanes pyxidiferum & 4 & 1,2 & 4 & 3,6 & 4 & 0,4 & 1,0 \\
\hline Asplenium gastonis & 3 & 0,9 & 3 & 2,7 & 3 & 0,3 & 1,0 \\
\hline Polypodium catharinae & 3 & 0,9 & 3 & 2,7 & 3 & 0,3 & 1,0 \\
\hline Tillandsia mallemontii & 2 & 0,6 & 2 & 1,8 & 2 & 0,2 & 1,0 \\
\hline Doryopteris nobilis & 1 & 0,3 & 1 & 0,9 & 1 & 0,1 & 1,0 \\
\hline Maxillaria acicularis & 1 & 0,3 & 1 & 0,9 & 1 & 0,1 & 1,0 \\
\hline Oncidium sp. & 1 & 0,3 & 1 & 0,9 & 1 & 0,1 & 1,0 \\
\hline Cryptophoranthus juergensii & 1 & 0,3 & 1 & 0,9 & 1 & 0,1 & 1,0 \\
\hline Tradescanthia sp. & 1 & 0,3 & 1 & 0,9 & 1 & 0,1 & 1,0 \\
\hline Vittaria lineata & 1 & 0,3 & 1 & 0,9 & 1 & 0,1 & 1,0 \\
\hline
\end{tabular}

espécies de Lepismium (L. lumbriocoides e L. houlletianum) com nota média 1,4; outras 23 espécies obtiveram nota média igual a 1.

As cinco espécies (14\%) de maior VIE são responsáveis por $72 \%$ das ocorrências enquanto as 10 (30\%) espécies com menor VIE são responsáveis por apenas $2,2 \%$. O percentual de $95 \%$ das ocorrências é atingido com as 19 principias espécies (56\%).

As famílias mais importantes foram Polypodiaceae, Orchidaceae e Piperaceae, que juntas compõem cerca de $91 \%$ do VIE da amostra; somente Polypodiaceae é responsável por $66 \%$ do valor de importância total (tabela 3).

Em termos de representatividade genérica destacaram-se Microgramma, Pleopeltis e Polypodium, que juntos somam $63 \%$ do VIE total da amostra (tabela 3).

A copa foi o estrato com maior abundância de epífitas, totalizando um valor de abundância (VA = soma das notas de todas as espécies ocorrentes) igual a 622, seguido do fuste alto com VA $=308$ e do fuste baixo com $\mathrm{VA}=110$. A nota média obtida pelas espécies 
Tabela 3. Famílias e gêneros amostrados na área de floresta ombrófila mista aluvial do rio Bariguí da Repar/Petrobras, município de Araucária, Paraná, classificadas segundo o valor de importância total (VIEt = soma dos VIEs específicos).

\begin{tabular}{lrlr}
\hline Família & VIEt & Gênero & VIEt \\
\hline POLYPODICEAE & 65,96 & Microgramma & 27,31 \\
ORCHIDACEAE & 18,17 & Pleopeltis & 26,35 \\
PIPERACEAE & 7,12 & Polypodium & 9,23 \\
CACTACEAE & 4,52 & Capanemia & 7,88 \\
BROMELIACEAE & 2,69 & Peperomia & 7,12 \\
ASPLENIACEAE & 0,87 & Lepismium & 4,52 \\
HYMENOPHYLLACEAE & 0,38 & Pleurothallis & 4,13 \\
COMMELINACEAE & 0,10 & Campylocentrum & 3,94 \\
PTERIDACEAE & 0,10 & Campyloneurum & 2,50 \\
VITTARIACEAE & 0,10 & Tillandsia & 1,63 \\
& & Oncidium & 1,06 \\
& & Aechmea & 1,06 \\
& & Leptotes & 0,96 \\
& & Asplenium & 0,87 \\
& & Pecluma & 0,58 \\
& & Trichomanes & 0,38 \\
& & Doryopteris & 0,10 \\
& & Maxillaria & 0,10 \\
& & Cryptophoranthus & 0,10 \\
& & Tradescantia & 0,10 \\
\end{tabular}

também seguiu a mesma ordem, ficando 1,51 na copa, 1,21 no fuste alto e 1,05 no fuste baixo. A riqueza específica foi similar para todas as regiões, ficando em 24 espécies na copa e no fuste alto e 22 espécies no fuste baixo.

O número de espécies epifíticas ocorrentes em um mesmo forófito variou de 0 a 13 , sendo o número máximo observado em dois indivíduos de Sebastiania commersoniana (Euphorbiaceae), espécie forofítica que também teve um indivíduo com 11 espécies epifíticas e dois com 10 espécies. Um único indivíduo arbóreo (Hovenia dulcis - Rhamnaceae) não apresentou epífitas, enquanto quatro indivíduos apresentaram apenas uma espécie, nove apresentaram duas espécies (em sete destes as espécies foram Microgramma vacciniifolia e Pleopeltis angusta) e 15 apresentaram três espécies. A riqueza específica não mostrou correlação com o PAP e com a altura dos forófitos $(\mathrm{p}>0,05)$.

Quanto à abundância epifítica nos forófitos, o VA máximo observado sobre um indivíduo forofítico foi 24 (também em $S$. commersoniana), seguido por dois outros (S. commersoniana e Schinus terebinthifolius Anacardiaceae) com VA $=21$; outros 10 indivíduos obtiveram VA igual ou superior a 15. O VA, assim como a riqueza específica, não apresentou correlação significativa com o PAP ( $p>0,05)$, apesar de apresentá-la com a altura dos forófitos (Spearman $=$ $0,6273, \mathrm{p}<0,05)$.

\section{Discussão}

A riqueza específica observada na área pode ser considerada baixa (tabela 4), principalmente quando comparada com a de formações florestais mais úmidas (Waechter 1986, 1992 (Torres), Fontoura et al. 1997, Kersten \& Silva 2001), embora seja maior que em outros trabalhos realizados com o componente epifítico vascular em florestas sujeitas a um clima subtropical (Aguiar et al. 1981, Cervi \& Dombrowski 1985, Cervi et al. 1988, Waechter 1992 (Taim), Dislich \& Mantovani 1998). No entanto, em trabalho semelhante, Dittrich et al. (1999) encontraram 74 espécies de epífitos vasculares no Parque Barigüi (menos de $15 \mathrm{~km}$ em linha reta da área estudada), 23 a mais que neste trabalho. Tal diferença se deve, em parte, à área amostral muito maior no Parque Bariguii (aproximadamente 50 ha) do que na REPAR (cerca de 8,6 ha). Outro fator que pode estar influenciando tal diferença é o estádio de desenvolvimento da vegetação nas localidades consideradas, pois o Parque Barigüi representa uma área 
Tabela 4. Índices de similaridade (Jaccard) entre o componente epifítico vascular de diversas áreas do Brasil em comparação com a área estudada, classificados em ordem decrescente de similaridade.

\begin{tabular}{lcccl}
\hline Local & N. spp. & Jaccard & H' & Referências \\
\hline Curitiba 1 & 74 & 0,374 & - & Dittrich et al. 1999 \\
Curitiba 2 & 33 & 0,192 & - & Cervi \& Dombrowski 1985; Cervi et al. 1988 \\
Osório & 53 & 0,182 & 2,990 & Waechter 1998 \\
Taim & 24 & 0,172 & 2,886 & Waechter 1992 \\
Torres 2 & 85 & 0,133 & 4,049 & Waechter 1992 \\
São Paulo & 37 & 0,128 & - & Dislish \& Mantovani 1998 \\
Montenegro/Triunfo & 17 & 0,115 & - & Aguiar et al. 1981 \\
Torres 1 & 120 & 0,096 & - & Waechter 1986 \\
Ilha do Mel & 77 & 0,067 & 3,608 & Kersten \& Silva 2001 \\
Macaé & 307 & 0,041 & - & Fontoura et al. 1997 \\
Ubatuba & 26 & 0,013 & - & Piliackas et al. 2000 \\
\hline
\end{tabular}

de floresta mais desenvolvida, enquanto a área estudada é uma floresta mais jovem, com diversidade e riqueza dos estratos arbóreos bem inferiores.

As três famílias mais ricas (Orchidaceae, Polypodiaceae e Bromeliaceae), que juntas totalizam 34 espécies (67\%), são também as famílias epifíticas mundialmente mais ricas (Madison 1977, Kress 1986, Benzing 1990), assim como nos neotrópicos (Gentry \& Dodson 1987). Diversos trabalhos de levantamento realizados em florestas sob clima subtropical também apresentaram estas famílias como as mais ricas (Cervi et al. 1988, Cervi \& Dombrowski 1985, Waechter 1992, 1998, Dislich \& Mantovani 1998, Dittrich et al. 1999).

Outros estudos pontuais realizados em "floresta com Araucária" ou em "florestas sob clima estacional" no Brasil (Aguiar et al. 1981, Cervi \& Dombrowski 1985 e Cervi et al. 1988, Waechter 1992 (Taim), Dislich \& Mantovani 1998) apontaram, analogamente a este estudo, os gêneros Tillandsia (Bromeliaceae), Peperomia (Piperaceae) e Oncidium (Orchidaceae) como os mais ricos. No entanto, Pleurothallis foi o gênero mais bem representado apenas em Dittrich $e t$ al. (1999).

O trabalho clássico de Maack (1981) descrevendo a vegetação do Paraná, salientou a riqueza de epífitas na floresta com Araucaria, citando Bromeliaceae, Polypodiaceae (lato sensu), Orchidaceae, Hymenophyllaceae e Araceae como as famílias "que mais chamam atenção". Destas, as duas últimas não se destacaram no presente estudo, sendo Hymenophyllaceae representada por somente uma espécie (Trichomanes pyxidiferum), enquanto Araceae não foi registrada na área analisada. Quanto à representatividade genérica, Maack (1981) destacou o gênero Oncidium, representado neste trabalho por quatro espécies, como o gênero de orquídea "de maior frequiência na mata de araucária". Dos demais gêneros mencionados por este autor somente Pleurothallis e Maxillaria foram observados na área da Repar, sendo o primeiro aquele que teve o maior número de espécies registradas (seis).

Quanto às formas de vida ocorrentes entre as espécies registradas, a predominância de holoepífitos característicos sobre as demais categorias foi também observada por Dittrich et al. (1999) em uma área de floresta com Araucaria, por Pinto et al. (1995) e Dislich \& Mantovani (1998), ambos em floresta estacional semidecidual no estado de São Paulo, por Waechter (1992) e Kersten \& Silva (2001) para áreas de planície costeira no sul do país.

Em termos de similaridade específica a área mais próxima à estudada foi o Parque Barigüi, em Curitiba (Dittrich et al. 1999), seguida de outra área do mesmo município, estudada por Cervi \& Dombrowski (1985) e Cervi et al. (1988), ambas de floresta com Araucaria (tabela 4).

Conforme o índice de Jaccard, com exceção da área denominada Torres 2 (Waechter 1986), as formações subtropicais (Aguiar et al. 1981, Cervi \& Dombrowski 1985, Cervi et al. 1988, Waechter 1992 (Taim), Dislich \& Mantovani 1998, Waechter 1998, Dittrich et al. 1999) assemelharam-se floristicamente mais à área estudada do que às áreas situadas em zona de ocorrência das florestas tropicais (Waechter 1992 - Torres 1, Fontoura et al. 1997, Piliackas 2000, Kersten \& Silva 2001). Possivelmente os maiores valores de similaridade encontrados entre a área analisada e as demais citadas acima deve-se ao fato destas localidades estarem 
sujeitas a tipos climáticos com caraterísticas comuns, notadamente relacionadas às temperaturas relativamente mais baixas, com invernos mais rigorosos e/ou secos.

$\mathrm{Na}$ amostragem quantitativa foram representadas cerca de $67 \%$ do total de espécies, $75 \%$ dos gêneros e $75 \%$ das famílias em relação ao levantamento qualitativo da área como um todo. Apesar de terem sido representadas pouco menos de $3 / 4$ das espécies observadas no inventário florístico, considera-se que o esforço amostral foi suficiente, principalmente devido à baixa diversidade, inferior à região do Taim estudada por Waechter (1992) com $\mathrm{H}^{\prime}=2,8$, ao grande número de forófitos observados com até 3 espécies $(29=26 \%)$ e ao fato de que as espécies observadas somente no inventário florístico terem sido observadas uma ou poucas vezes na área. A diversidade não foi apenas mais baixa que a do Taim (Waechter 1992), foi mais baixa que a registrada em qualquer outro estudo com epífitas vasculares (Tabela 4). O principal fator a contribuir para tal fato é o estádio de desenvolvimento da floresta considerada. Sendo uma formação relativamente nova apresenta principalmente espécies pioneiras de rápida colonização e mais resistentes a falta d'água, caso típico das pterodófitas, principal grupo amostrado.

A espécie com maior valor de importância (Microgramma squamulosa - Polypodiaceae) também ocorreu em vários outros levantamentos, estando ausente somente nas áreas estudadas por Piliackas et al. (2000) e Kersten \& Silva (2001). A segunda espécie em importância (Pleopeltis angusta - Polypodiaceae) foi citada para todas as localidades consideradas na comparação florística (tabela 4), exceto Ubatuba (Piliackas et al. 2000). Observações pessoais realizadas na cidade de Curitiba evidenciaram que estas espécies são freqüentes e abundantes sobre árvores usadas na arborização urbana, o que mostra que podem ser consideradas pioneiras no ambiente epifítico. Estas espécies destacaram-se na área da Repar pelos altos valores de importância obtidos. Em nenhuma outra localidade analisada nas comparações qualquer espécie obteve índices tão altos, sendo os mais próximos aqueles obtidos por Kersten \& Silva (2001) para Microgramma vacciniifolia (ca. 11), em floresta da planície litorânea da Ilha do Mel, PR. As quatro principais espécies juntas respondem por $70 \%$ do VIE e por $63 \%$ das ocorrências (tabela 2). Estas já foram, inclusive, chamadas por Claver et al. (1983) de "ervas daninhas epifíticas".

No outro extremo, o número de espécies raras pode ser considerado elevado. Seis espécies (12\%) foram observadas apenas uma vez nos estudos quantitativos.
Se consideradas ainda as espécies registradas somente para o estudo florístico obtém-se percentual de $45 \%$ (23 espécies) de raras.

Aechmea distichantha (Bromeliaceae) recebeu as maiores notas médias de abundância, principalmente devido ao seu grande porte (suas rosetas foliares podem ultrapassar $1 \mathrm{~m}$ de diâmetro), pois raramente são observadas muitas em um mesmo estrato ou árvore na região. Microgramma squamulosa e Pleopeltis angusta, ao contrário, possuem pequeno porte, mas distribuem-se pelo forófito ocupando área significativa de sua superfície, a primeira devido à sua forma de crescimento longoreptante e ambas ao tipo de reprodução esporocórica que facilita o estabelecimento de diversos indivíduos em uma área pequena. As duas outras espécies de Cactaceae que obtiveram média superior a um (Lepismium lumbricoides e L. houlletianum) apresentam porte inferior ao da Bromeliaceae citada, tal qual ocorre com as Polypodiaceae, porém distribuem-se tanto vertical (ramos pendentes) como horizontalmente (ramos radicantes) sobre os forófitos.

Em relação às famílias mais importantes, Polypodiaceae (tabela 3) destacou-se em função de abrigar três das quatro espécies mais importantes (tabela 2), com VIE total cerca de três vezes superior ao da segunda família (Orchidaceae), que se destacou devido, principalmente, ao grande número de espécies observadas na amostragem (16). Piperaceae, representada por somente uma espécie (Peperomia catharinae), destacou-se em função da alta freqüência com que ocorreu na amostragem.

A distribuição vertical dos epífitos na floresta é decorrente de fatores como umidade, luminosidade e disponibilidade de espaço (Benzing 1990). Nas copas das árvores, além de boas condições de luminosidade, o maior número de ramificações aumenta a superfície para a fixação das epífitas, aumentando, consequientemente, a abundância. Tal fato foi também observado em outros estudos realizados (e.g. Waechter 1992 (Torres e Taim)), embora contrarie o observado por Kersten \& Silva (2001), onde os intervalos mais ricos em espécies epifíticas foram os inferiores, correspondentes neste estudo aos estratos denominados de fuste baixo e fuste alto. A maior abundância observada no fuste alto em relação ao fuste baixo, assim como a correlação existente entre o VA e a altura dos forófitos, parecem indicar que a passagem do ambiente terrícola para o epifítico foi realmente uma migração em busca de luz (Benzing 1990), muito embora, o 
estresse hídrico seja o principal desafio para as epífitas. São necessários, no entanto, estudos complementares para a comprovação de tais informações.

Agradecimentos - à Universidade Federal do Paraná pela oportunidade de desenvolvimento deste trabalho; a Marília Borgo e Yoshiko S. Kuniyoshi pelo auxílio nos trabalhos de campo; ao Prof. Dr. Adaucto Bellarmino de Pereira Netto, pela elaboração do abstract; ao Sr. Gert Hatschbach por algumas determinações específicas realizadas; ao Sr. Ernani Zamberlan (Petrobras) pelo apoio logístico e ao Dr. Carlos V. Roderjan, coordenador do Programa Vegetação do convênio Repar/Funpar, pela oportunidade de realização deste estudo.

\section{Referências bibliográficas}

AGUIAR, L.W., CITADINI-ZANETTE, V., MARTAU, L. \& BACKES, A. 1981. Composição florística de epífitos vasculares numa área localizada nos municípios de Montenegro e Triunfo, Rio Grande do Sul, Brasil. Iheringia (Série Botânica) 28:55-93.

BENZING, D.H. 1990. Vascular epiphytes. Cambridge University Press, Cambridge.

BRUMMITT, R.K. \& POWELL, C.E. 1992. Authors of plant names. $1^{\text {st }}$ ed. Royal Botanic Gardens, Kew.

CERVI, A.C. \& DOMBROWSKI, L.T.D. 1985. Bromeliaceae de um capão de floresta primária do Centro Politécnico de Curitiba (Paraná, Brasil). Fontqueria 9:9-11.

CERVI, A.C., ACRA, L.A., RODRIGUES, L., TRAIN, S., IVACHECHEN, S.L. \& MOREIRA, A.L.O.R. 1988. Contribuição ao conhecimento das epífitas (exclusive Bromeliaceae) de uma floresta de araucária do primeiro planalto paranaense. Ínsula 18:75-82.

CLAVER, F.K., ALANIS, J.R. \& CALDIS, D.O. 1983. Tillandsia spp.: epiphytic weeds of trees and brushes. Forest ecological management 6:367-372.

DISLICH, R. \& MANTOVANI, W. 1998. Flora de epífítas vasculares da Reserva da Cidade Universitária "Armando de Salles Oliveira" (São Paulo, Brasil). Boletim de Botânica da Universidade de São Paulo 17:61-83.

DITTRICH, V.A.O., KOZERA, C. \& SILVA, S.M. 1999. Levantamento florístico de epífitos vasculares no Parque Bariguii, Paraná, Brasil. Iheringia (Série Botânica) 52:11-22.

FONTOURA, T., SYLVESTRE, L.S., VAZ, A.M.S. \& VIEIRA, C.M. 1997. Epífitas vasculares, hemiepífitas e hemiparasitas da Reserva Ecológica de Macaé de Cima. In Serra de Macaé de Cima: diversidade florística e conservação da Mata Atlântica (H.C. Lima \& R.R Guedes-Bruni, eds.). Editora do Jardim Botânico do Rio de Janeiro, Rio de Janeiro, p. 89-101.
GENTRY, A.H. \& DODSON, C.H. 1987. Diversity and biogeography of neotropical vascular epiphytes. Annals of Missouri Botanical Garden 74:205-233.

INDEX KEWENSIS 1993. Cambridge University Press, Cambridge on compact disc (versão 1.0).

KERSTEN, R.A. \& SILVA, S.M. 2001. Composição florística e distribuição espacial de epífitas vasculares em floresta da planície litorânea da Ilha do Mel, Paraná, Brasil. Revista Brasileira de Botânica 24:213-226.

KREBS, C.J. 1998. Ecological Methodology, $2^{\text {nd }}$ ed. Ed. Addison Wesley - Longmann, Menlo Park.

KRESS, W.J. 1986. The systematic distribution of vascular epiphytes: an update. Selbyana 9:2-22.

LABIAK, P.H. \& PRADO, J. 1998. Pteridófitas epífitas da Reserva Volta Velha, Itapoá - Santa Catarina, Brasil. Boletim do Instituto de Botânica 11:1-79.

MAACK, R. 1981. Geografia física do estado do Paraná. $2^{\mathrm{a}}$ ed. Ed. José Olympio, Rio de Janeiro.

MADISON, M. 1977. Vascular epiphytes: their systematic occurrence and salient features. Selbyana 2:1-13.

PILIACKAS, J.M., BARBOSA, L.M. \& CATHARINO, E.L.M. 2000. Levantamento das epífitas vasculares do manguezal do Rio Picinguaba, Ubatuba, São Paulo. In Anais do $5^{\circ}$ Simpósio de Ecossistemas Brasileiros. (S. Watanabe, coord.). Aciesp, São Paulo, v. 2, p.357-363.

PINTO, A.C., DEMATTÊ, M.E.S.P. \& PAVANI, M.C.M.D. 1995. Composição florística de epífitas (Magnoliophyta) em fragmento de floresta no município de Jaboticabal, SP, Brasil. Científica 22:283-289.

SIQUEIRA, J.D.P., RODERJAN, C.V., KIRCHNER, F.F. \& SOUSA, L.C.P. 2001. Diagnóstico e monitoramento da cobertura vegetal da área de influência direta e indireta do vazamento de óleo de refinaria Presidente Getúlio Vargas - Repar, Araucária/PR, Fase 1 - Diagnóstico. Petróleo Brasileiro S/A (Petrobras), Fundação da Universidade Federal do Paraná para o desenvolvimento de Ciência da Tecnologia e da Cultura (Funpar), Curitiba.

VELOSO, H. P., RANGEL FILHO, A.L. \& LIMA, J.C. 1991. Classificação da vegetação brasileira adaptada a um sistema universal. Instituto Brasileiro de Geografia e Estatística, Rio de Janeiro.

WAECHTER, J.L. 1986. Epífitos vasculares da mata paludosa do Faxinal, Torres, Rio Grande do Sul, Brasil. Iheringia (Série Botânica) 34:39-49.

WAECHTER, J.L. 1992. O epifitismo vascular na planície costeira do Rio Grande do Sul. Tese de doutorado, Universidade Federal de São Carlos, São Carlos.

WAECHTER, J.L. 1998. Epifitismo vascular em uma floresta de restinga do Brasil Subtropical. Revista Ciência e Natura 20:43-66. 